\title{
Fixed Points of Multivalued Quasi-nonexpansive Mappings Using a Faster Iterative Process
}

\author{
Safeer Hussain KHAN \\ Department of Mathematics, Statistics and Physics, Qatar University, Doha 2713, Qatar \\ E-mail:safeer@qu.edu.qa \\ Mujahid ABBAS \\ Department of Mathematics and Applied Mathematics, University of Pretoria, Lynnwood road, \\ Pretoria 0002, South Africa \\ E-mail: mujahidabbas14@yahoo.com \\ Sartaj ALI \\ Department of Mathematics, National College of Business Administration and Economics, \\ Lahore, Pakistan \\ E-mail:sartajali2004@yahoo.com
}

\begin{abstract}
In this article, we prove some strong and weak convergence theorems for quasi-nonexpansive multivalued mappings in Banach spaces. The iterative process used is independent of Ishikawa iterative process and converges faster. Some examples are provided to validate our results. Our results extend and unify some results in the contemporary literature.
\end{abstract}

Keywords Multivalued nonexpansive mapping, common fixed point, condition (I), weak and strong convergence

MR(2010) Subject Classification 47H10, 54H 25

\section{Introduction and Preliminaries}

Throughout this article, $\mathbb{N}$ denotes the set of positive integers. Let $E$ be a real Banach space. A subset $K$ is called proximinal if for each $x \in E$, there exists an element $k \in K$ such that $d(x, k)=\inf \{\|x-y\|: y \in K\}=d(x, K)$. It is known that weakly compact convex subsets of a Banach space and closed convex subsets of a uniformly convex Banach space are proximinal. We denote the family of nonempty proximinal bounded subsets of $K$ by $\mathcal{P}(K)$. It is well known that if $K$ is proximinal subset of $E$, then $K$ is closed. Consistent with [6], let $\mathrm{CB}(K)$ be the class of all nonempty bounded and closed subsets of $K$. Let $H$ be a Hausdorff metric induced by the metric $d$ of $E$, that is,

$$
H(A, B)=\max \left\{\sup _{x \in A} d(x, B), \sup _{y \in B} d(y, A)\right\}
$$


for every $A, B \in \mathrm{CB}(E)$. A point $x \in K$ is called a fixed point of a multivlaued mapping $T: K \rightarrow \mathrm{CB}(K)$ if $x \in T x$. A set of all fixed points of $T$ is denoted by $F(T)$. A multivalued mapping $T: K \rightarrow \mathrm{CB}(K)$ is said to be: (a) nonexpansive if $H(T x, T y) \leq\|x-y\|$ for all $x, y \in K$; (b) quasi-nonexpansive mapping if $H(T x, p) \leq\|x-p\|$ for all $x \in K$ and $p \in F(T)$. It is known that every nonexpansive multivalued map $T$ with $F(T) \neq \emptyset$ is quasi nonexpansive but the converse is not true. The study of fixed points for multivalued mappings using the Hausdorff metric was initiated by Markin [5] (see also [6]). Multivalued fixed point theory has applications in control theory, convex optimization, differential inclusion, and economics (see [2] and references cited therein). The theory of multivalued mappings is harder than the corresponding theory of single-valued mappings. Different iterative processes have been used to approximate the fixed points of multivalued mappings. Among these iterative processes, Sastry and Babu [9] considered the following.

Let $K$ be a nonempty convex subset of $E, T: K \rightarrow \mathcal{P}(K)$ a multivalued mapping with $p \in T p$.

(i) The sequences of Mann iterates is defined by $x_{1} \in K$,

$$
x_{n+1}=\left(1-a_{n}\right) x_{n}+a_{n} y_{n},
$$

where $y_{n} \in T x_{n}$ is such that $\left\|y_{n}-p\right\|=d\left(p, T x_{n}\right)$ and $\left\{a_{n}\right\}$ is a sequence of numbers in $(0,1)$ satisfying $\lim _{n \rightarrow \infty} a_{n}=0$ and $\sum_{n=1}^{\infty} a_{n}=\infty$.

(ii) Ishikawa iterative process is defined by starting with $x_{1} \in K$ and defining

$$
\left\{\begin{array}{l}
y_{n}=\left(1-b_{n}\right) x_{n}+b_{n} z_{n}, \\
x_{n+1}=\left(1-a_{n}\right) x_{n}+a_{n} u_{n},
\end{array}\right.
$$

where $z_{n} \in T x_{n}, u_{n} \in T y_{n}$ are such that $\left\|z_{n}-p\right\|=d\left(p, T x_{n}\right)$ and $\left\|u_{n}-p\right\|=d\left(p, T y_{n}\right)$, and $\left\{a_{n}\right\},\left\{b_{n}\right\}$ are real sequences of numbers with $0 \leq a_{n}, b_{n}<1$ satisfying $\lim _{n \rightarrow \infty} b_{n}=0$ and $\sum a_{n} b_{n}=\infty$.

Panyanak [8] generalized the results proved by Sastry and Babu [9].

The following lemma due to Nadler [6] is very useful.

Lemma 1.1 Let $A, B \in \mathrm{CB}(E)$ and $a \in A$. If $\eta>0$, then there exists $b \in B$ such that $d(a, b) \leq H(A, B)+\eta$.

Based on the above lemma, Song and Wang [14] modified the iterative process due to Panyanak [8] and improved the results presented there. They used (1.2) but with $a_{n} \in$ $[0,1] ; b_{n} \in[0,1]$ with $\lim _{n \rightarrow \infty} b_{n}=0$ and $\sum_{n=1}^{\infty} a_{n} b_{n}=\infty ; z_{n} \in T x_{n}, u_{n} \in T y_{n}$ with $\left\|z_{n}-u_{n}\right\| \leq H\left(T x_{n}, T y_{n}\right)+\eta_{n}$ and $\left\|z_{n+1}-u_{n}\right\| \leq H\left(T x_{n+1}, T y_{n}\right)+\eta_{n}$, where $\eta_{n} \in(0, \infty)$ such that $\lim _{n \rightarrow \infty} \eta_{n}=0$.

It is to be noted that Song and Wang [14] needed the condition $T p=\{p\}$ in order to prove their Theorem 1. Actually, Panyanak [8] proved some results using Ishikawa type iterative process without this condition. Song and Wang [14] showed that without this condition his process was not well-defined. They reconstructed the process using the condition $T p=\{p\}$ which made it well-defined. Such a condition was also used by Jung [3]. Later, Shazad and Zegeye [12] got rid of this condition by using $P_{T}(x)=\{y \in T x:\|x-y\|=d(x, T x)\}$ for a 
multivalued mapping $T: K \rightarrow \mathcal{P}(K)$. They proved a couple of strong convergence results using Ishikawa type iterative process.

Khan and Yildirim [4] used the following iterative process using the method of direct construction of Cauchy sequence and without using the condition $T p=\{p\}$ for any $p \in F(T)$ :

$$
\left\{\begin{array}{l}
x_{1} \in K, \\
x_{n+1}=(1-\lambda) v_{n}+\lambda u_{n}, \\
y_{n}=(1-\eta) x_{n}+\eta v_{n}, n \in \mathbb{N},
\end{array}\right.
$$

where $v_{n} \in P_{T}\left(x_{n}\right), u_{n} \in P_{T}\left(y_{n}\right)$ and $0<\lambda, \eta<1$.

Let us now construct the following iterative process for a multivalued mapping $T: K \rightarrow$ $\mathcal{P}(K)$ with the help of $P_{T}$ defined above.

Let $K$ be a nonempty convex subset of $E, \alpha_{n}, \beta_{n}, \gamma_{n} \in[0,1]$. Start with choosing $x_{1} \in K$ and $u_{1} \in P_{T}\left(x_{1}\right)$ and let

$$
z_{1}=\left(1-\gamma_{1}\right) x_{1}+\gamma_{1} u_{1}
$$

Choose $w_{1} \in P_{T}\left(z_{1}\right)$ such that

$$
y_{1}=\left(1-\beta_{1}\right) u_{1}+\beta_{1} w_{1}
$$

Choose $v_{1} \in P_{T}\left(y_{1}\right)$ such that

$$
x_{2}=\left(1-\alpha_{1}\right) v_{1}+\alpha_{1} w_{1} .
$$

Now choose $u_{2} \in P_{T}\left(x_{2}\right)$ such that

$$
z_{2}=\left(1-\gamma_{2}\right) x_{2}+\gamma_{2} u_{2} .
$$

Choose $w_{2} \in P_{T}\left(z_{2}\right)$ such that

$$
y_{2}=\left(1-\beta_{2}\right) u_{2}+\beta_{2} w_{2} .
$$

Choose $v_{2} \in P_{T}\left(y_{2}\right)$ such that

$$
x_{3}=\left(1-\alpha_{2}\right) v_{2}+\alpha_{2} w_{2} .
$$

Next, choose $u_{3} \in P_{T}\left(x_{3}\right)$ such that

$$
z_{3}=\left(1-\gamma_{3}\right) x_{3}+\gamma_{3} u_{3} .
$$

Choose $w_{3} \in P_{T}\left(z_{3}\right)$ such that

$$
y_{3}=\left(1-\beta_{3}\right) u_{3}+\beta_{3} w_{3} .
$$

Choose $v_{3} \in P_{T}\left(y_{3}\right)$ such that

$$
x_{4}=\left(1-\alpha_{3}\right) v_{3}+\alpha_{3} w_{3} .
$$

Inductively, we obtain

$$
\begin{aligned}
& x_{n+1}=\left(1-\alpha_{n}\right) v_{n}+\alpha_{n} w_{n}, \\
& y_{n}=\left(1-\beta_{n}\right) u_{n}+\beta_{n} w_{n}, \\
& z_{n}=\left(1-\gamma_{n}\right) x_{n}+\gamma_{n} u_{n},
\end{aligned}
$$

where $u_{n} \in P_{T}\left(x_{n}\right), v_{n} \in P_{T}\left(y_{n}\right), w_{n} \in P_{T}\left(z_{n}\right)$. Its single-valued version was used by Abbas and Nazir [1]. 
In this paper, we use the following simplified version of (1.3):

$$
\begin{aligned}
& x_{n+1}=(1-\alpha) v_{n}+\alpha w_{n}, \\
& y_{n}=(1-\beta) u_{n}+\beta w_{n}, \\
& z_{n}=(1-\gamma) x_{n}+\gamma u_{n},
\end{aligned}
$$

where $\alpha, \beta, \gamma \in[0,1], u_{n} \in P_{T}\left(x_{n}\right), v_{n} \in P_{T}\left(y_{n}\right)$ and $w_{n} \in P_{T}\left(z_{n}\right)$.

Note that we are using $\alpha, \beta$ and $\gamma$ only for the sake of simplicity and $\alpha_{n}, \beta_{n}$ and $\gamma_{n}$ could be used equally well under suitable conditions. This scheme is independent of both Mann and Ishikawa iterative processes neither reduce to the other. Moreover, it is faster than all of Picard, Mann and Ishikawa iterative processes in case of contractions [1]. Thus our results are independent but better (in the sense of speed of convergence of our iterative process) and more general (in view of more general class of mappings) than corresponding results of Shazad and Zegeye [12], Khan and Yildirim [4] and Song and Cho [13] and the results generalized therein.

At this stage, we recall the following. A Banach space $E$ is said to satisfy Opial's condition [7] if for any sequence $\left\{x_{n}\right\}$ in $E, x_{n} \rightarrow x$ implies that

$$
\limsup _{n \rightarrow \infty}\left\|x_{n}-x\right\|<\limsup _{n \rightarrow \infty}\left\|x_{n}-y\right\|
$$

for all $y \in E$ with $y \neq x$. Examples of Banach spaces satisfying Opial's condition are Hilbert spaces and all $l^{p}$ spaces $(1<p<\infty)$. On the other hand, $L^{p}[0,2 \pi]$ with $1<p \neq 2$ fails to satisfy this condition. A multivalued mapping $T: K \rightarrow \mathrm{CB}(K)$ is called demiclosed at $y \in K$ if for any sequence $\left\{x_{n}\right\}$ in $K$ weakly convergent to $x$ and $y_{n} \in T x_{n}$ strongly convergent to $y$, we have $y \in T x$.

Now we state some useful lemmas.

Lemma $1.2([13])$ Let $T: K \rightarrow \mathcal{P}(K)$ be a multivalued mapping and $P_{T}(x)=\{y \in T x$ : $\|x-y\|=d(x, T x)\}$. Then the following are equivalent:

(1) $x \in F(T)$;

(2) $P_{T}(x)=\{x\}$

(3) $x \in F\left(P_{T}\right)$.

Moreover, $F(T)=F\left(P_{T}\right)$.

Lemma 1.3 ([10]) Let $E$ be a uniformly convex Banach space and $0<p \leq t_{n} \leq q<1$ for all $n \in \mathbb{N}$. Suppose that $\left\{x_{n}\right\}$ and $\left\{y_{n}\right\}$ are two sequences of $E$ such that $\lim _{\sup _{n \rightarrow \infty}}\left\|x_{n}\right\| \leq$ $r$, $\limsup _{n \rightarrow \infty}\left\|y_{n}\right\| \leq r$ and $\lim _{n \rightarrow \infty}\left\|t_{n} x_{n}+\left(1-t_{n}\right) y_{n}\right\|=r$ hold for some $r \geq 0$. Then $\lim _{n \rightarrow \infty}\left\|x_{n}-y_{n}\right\|=0$.

\section{Main Results}

Lemma 2.1 Let $E$ be a normed space and $K$ be a nonempty closed convex subset of $E$. Let $T: K \rightarrow \mathcal{P}(K)$ be a multivalued mapping such that $F(T) \neq \emptyset$ and $P_{T}$ be a quasi-nonexpansive mapping. Let $\left\{x_{n}\right\}$ be the sequence as defined in (1.4). Then $\lim _{n \rightarrow \infty}\left\|x_{n}-p\right\|$ exists for all $p \in F(T)$ and $\lim _{n \rightarrow \infty} d\left(x_{n}, P_{T}\left(x_{n}\right)\right)=0$.

Proof To prove that $\lim _{n \rightarrow \infty}\left\|x_{n}-p\right\|$ exists, we consider

$$
\left\|x_{n+1}-p\right\|=\left\|(1-\alpha) v_{n}+\alpha w_{n}-p\right\|
$$




$$
\begin{aligned}
& \leq(1-\alpha)\left\|v_{n}-p\right\|+\alpha\left\|w_{n}-p\right\| \\
& \leq(1-\alpha) H\left(P_{T}\left(y_{n}\right), P_{T}(p)\right)+\alpha H\left(P_{T}\left(z_{n}\right), P_{T}(p)\right) \\
& \leq(1-\alpha)\left\|y_{n}-p\right\|+\alpha\left\|z_{n}-p\right\| .
\end{aligned}
$$

Next

$$
\begin{aligned}
\left\|y_{n}-p\right\| & =\left\|(1-\beta) u_{n}+\beta w_{n}-p\right\| \\
& \leq(1-\beta)\left\|u_{n}-p\right\|+\beta\left\|w_{n}-p\right\| \\
& \leq(1-\beta) H\left(P_{T}\left(x_{n}\right), P_{T}(p)\right)+\beta H\left(P_{T}\left(z_{n}\right), P_{T}(p)\right) \\
& \leq(1-\beta)\left\|x_{n}-p\right\|+\beta\left\|z_{n}-p\right\| .
\end{aligned}
$$

And

$$
\begin{aligned}
\left\|z_{n}-p\right\| & =\left\|(1-\gamma) x_{n}+\gamma u_{n}-p\right\| \\
& \leq(1-\gamma)\left\|x_{n}-p\right\|+\gamma\left\|u_{n}-p\right\| \\
& \leq(1-\gamma)\left\|x_{n}-p\right\|+\gamma H\left(P_{T}\left(x_{n}\right), P_{T}(p)\right) \\
& \leq(1-\gamma)\left\|x_{n}-p\right\|+\gamma\left\|x_{n}-p\right\| \\
& =\left\|x_{n}-p\right\| .
\end{aligned}
$$

Thus

$$
\left\|y_{n}-p\right\| \leq\left\|x_{n}-p\right\|
$$

and hence $\left\|x_{n+1}-p\right\| \leq\left\|x_{n}-p\right\|$. This implies that $\lim _{n \rightarrow \infty}\left\|x_{n}-p\right\|$ exists for each $p \in F(T)$. Suppose that

$$
\lim _{n \rightarrow \infty}\left\|x_{n}-p\right\|=c
$$

where $c \geq 0$.

We now prove that

$$
\lim _{n \rightarrow \infty} d\left(x_{n}, T x_{n}\right)=0 .
$$

The case when $c=0$ is obvious. We thus assume that $c>0$. Inasmuch as $d\left(x_{n}, T x_{n}\right) \leq$ $\left\|x_{n}-u_{n}\right\|$, it suffices to prove that $\lim _{n \rightarrow \infty}\left\|x_{n}-u_{n}\right\|=0$.

Now

$$
\left\|u_{n}-p\right\| \leq H\left(P_{T}\left(x_{n}\right), P_{T}(p)\right) \leq\left\|x_{n}-p\right\|
$$

implies that

$$
\limsup _{n \rightarrow \infty}\left\|u_{n}-p\right\| \leq c
$$

From (2.1) and (2.2), we obtain

$$
\limsup _{n \rightarrow \infty}\left\|z_{n}-p\right\| \leq c
$$

and

$$
\limsup _{n \rightarrow \infty}\left\|y_{n}-p\right\| \leq c
$$

Noting that

$$
\left\|v_{n}-p\right\| \leq H\left(P_{T}\left(y_{n}\right), P_{T}(p)\right) \leq\left\|y_{n}-p\right\| \leq\left\|x_{n}-p\right\|,
$$


we have

$$
\limsup _{n \rightarrow \infty}\left\|v_{n}-p\right\| \leq c
$$

Similarly,

$$
\limsup _{n \rightarrow \infty}\left\|w_{n}-p\right\| \leq c
$$

Moreover,

$$
\begin{aligned}
\lim _{n \rightarrow \infty}\left\|x_{n+1}-p\right\| & =\lim _{n \rightarrow \infty}\left\|(1-\alpha) v_{n}+\alpha w_{n}-p\right\| \\
& =\lim _{n \rightarrow \infty}\left\|(1-\alpha)\left(v_{n}-p\right)+\alpha\left(w_{n}-p\right)\right\|=c .
\end{aligned}
$$

From (2.7)-(2.9) and Lemma 1.3, we have

$$
\lim _{n \rightarrow \infty}\left\|v_{n}-w_{n}\right\|=0 .
$$

Together with this and

$$
\liminf _{n \rightarrow \infty}\left\|x_{n+1}-p\right\| \leq \liminf _{n \rightarrow \infty}\left(\left\|v_{n}-p\right\|+\alpha\left\|v_{n}-w_{n}\right\|\right),
$$

we obtain

$$
c \leq \liminf _{n \rightarrow \infty}\left\|v_{n}-p\right\| .
$$

Using (2.7), we have

$$
\lim _{n \rightarrow \infty}\left\|v_{n}-p\right\|=c .
$$

In a way similar to above, it follows that

$$
\lim _{n \rightarrow \infty}\left\|z_{n}-p\right\|=c
$$

That is,

$$
\begin{aligned}
\lim _{n \rightarrow \infty}\left\|z_{n}-p\right\| & =\left\|(1-\gamma) x_{n}+\gamma u_{n}-p\right\| \\
& =\left\|(1-\gamma)\left(x_{n}-p\right)+\gamma\left(u_{n}-p\right)\right\|=c .
\end{aligned}
$$

Hence, from (2.4) , (2.12) and Lemma 1.3, we have

$$
\lim _{n \rightarrow \infty}\left\|x_{n}-u_{n}\right\|=0,
$$

which yields $\lim _{n \rightarrow \infty} d\left(x_{n}, P_{T} x_{n}\right)=0$ as desired.

We are now all set to go for our first strong convergence theorem.

Theorem 2.2 Let $E$ be a real Banach space and $K$ be a nonempty compact convex subset of $E$. Let $T: K \rightarrow \mathcal{P}(K)$ be a multivalued mapping such that $F(T) \neq \emptyset$ and $P_{T}$ be quasi-nonexpansive mapping. Let $\left\{x_{n}\right\}$ be the sequence as defined in (1.4). Then $\left\{x_{n}\right\}$ converges strongly to a fixed point of $T$.

Proof We have proved in Lemma 2.1 that $\lim _{n \rightarrow \infty}\left\|x_{n}-p\right\|$ exists for all $p \in F(T)$. Now from the compactness of $K$, there exists a subsequence $\left\{x_{n_{k}}\right\}$ of $\left\{x_{n}\right\}$ such that $\lim _{k \rightarrow \infty}\left\|x_{n_{k}}-q\right\|=0$ for some $q \in K$. Then

$$
\begin{aligned}
d\left(q, P_{T}(q)\right. & \leq d\left(x_{n_{k}}, q\right)+d\left(x_{n_{k}}, P_{T}\left(x_{n_{k}}\right)+H\left(P_{T}\left(x_{n_{k}}\right), P_{T}(q)\right)\right. \\
& \leq\left\|x_{n_{k}}-q\right\|+\left\|x_{n_{k}}-u_{n_{k}}\right\|+\left\|x_{n_{k}}-q\right\| \rightarrow 0 \quad \text { as } n \rightarrow \infty
\end{aligned}
$$


because by Lemma 2.1 , we have $\lim _{n \rightarrow \infty}\left\|x_{n_{k}}-u_{n_{k}}\right\|=0$. That is, $d\left(q, P_{T}(q)\right)=0$. Hence, $q$ is a fixed point of $P_{T}$. Since the set of fixed points of $P_{T}$ is the same as that of $T$ by Lemma 1.2, therefore $\left\{x_{n}\right\}$ converges strongly to a fixed point of $T$.

Here is an example in support of the above theorem.

Example 2.3 Let $(\mathbb{R},\|\cdot\|)$ be a normed space with usual norm and $K=[0,1]$. Define $T: K \rightarrow \mathcal{P}(K)$ as

$$
T x=\left[0, \frac{2 x+1}{4}\right] \text {. }
$$

Obviously, $K$ is a compact convex subset of $\mathbb{R}$. Note that $F_{T}=\left[0, \frac{1}{2}\right] \neq \emptyset$. Let $\alpha=\beta=\gamma=\frac{1}{2}$. Observe that $P_{T}(x)=\{x\}$ when $x \in\left[0, \frac{1}{2}\right]$. In case $x \notin\left[0, \frac{1}{2}\right]$,

$$
\begin{aligned}
P_{T}(x) & =\left\{y \in T x:|y-x|=d\left(x,\left[0, \frac{2 x+1}{4}\right]\right)\right\} \\
& =\left\{y \in T x:|y-x|=\left|x-\frac{2 x+1}{4}\right|=\left|\frac{2 x-1}{4}\right|\right\} \\
& =\left\{y \in T x:|y-x|=\frac{2 x-1}{4}\right\} \\
& =\left\{y=\frac{2 x+1}{4}\right\} .
\end{aligned}
$$

We next prove that $P_{T}(x)$ is quasi-nonexpansive for all $x \in K$. The case of $\left[0, \frac{1}{2}\right]$ is trivial. Thus we take $x \in\left[\frac{1}{2}, 1\right]$.

$$
H\left(P_{T}(x), P_{T}(p)\right)=H\left(\frac{2 x+1}{4}, p\right)=\left|\frac{2 x+1}{4}-p\right| \leq|x-p|
$$

for all $x \in\left[\frac{1}{2}, 1\right]$. Finally, we generate a sequence $\left\{x_{n}\right\}$ as defined in (1.4) and show that it converges strongly to a fixed point of $T$.

Choose $x_{1}=1 \in K=[0,1]$. Then $P_{T}\left(x_{1}\right)=\frac{2 x_{1}+1}{4}=\frac{2(1)+1}{4}=\left\{\frac{1}{2}+\frac{1}{4}\right\}$ and $u_{1} \in P_{T}\left(x_{1}\right)=$ $\left\{\frac{1}{2}+\frac{1}{4}\right\}$. That is, $u_{1}=\frac{1}{2}+\frac{1}{4}$. Then

$$
z_{1}=(1-\gamma) x_{1}+\gamma u_{1}=\frac{1}{2}+\frac{1}{2}\left(\frac{1}{2}+\frac{1}{4}\right)=\frac{1}{2}+\frac{3}{8}
$$

and

$$
P_{T}\left(z_{1}\right)=\left\{\frac{2 z_{1}+1}{4}\right\}=\left\{\frac{2\left(\frac{1}{2}+\frac{3}{8}\right)+1}{4}\right\}=\left\{\frac{1}{2}+\frac{3}{16}\right\} .
$$

Choose $w_{1} \in P_{T}\left(z_{1}\right)=\left\{\frac{1}{2}+\frac{3}{16}\right\}$, that is, $w_{1}=\frac{1}{2}+\frac{3}{16}$. Then

$$
y_{1}=(1-\beta) u_{1}+\beta w_{1}=\frac{1}{2}\left(\frac{1}{2}+\frac{1}{4}\right)+\frac{1}{2}\left(\frac{1}{2}+\frac{3}{16}\right)=\frac{1}{2}+\frac{7}{32},
$$

and

$$
P_{T}\left(y_{1}\right)=\left\{\frac{2 y_{1}+1}{4}\right\}=\left\{\frac{2\left(\frac{1}{2}+\frac{7}{32}\right)+1}{4}\right\}=\left\{\frac{1}{2}+\frac{7}{64}\right\} .
$$

Choose $v_{1} \in P_{T}\left(y_{1}\right)=\left\{\frac{1}{2}+\frac{7}{64}\right\}, v_{1}=\frac{1}{2}+\frac{7}{64}$. Then

$$
\begin{aligned}
x_{2} & =(1-\alpha) v_{1}+\alpha w_{1} \\
& =\frac{1}{2}\left(\frac{1}{2}+\frac{7}{64}\right)+\frac{1}{2}\left(\frac{1}{2}+\frac{3}{16}\right)=\frac{1}{2}+\frac{19}{128}<\frac{1}{2}+\frac{1}{4},
\end{aligned}
$$




$$
P_{T}\left(x_{2}\right)=\left\{\frac{2 x_{2}+1}{4}\right\}=\left\{\frac{2\left(\frac{1}{2}+\frac{19}{128}\right)+1}{4}\right\}=\left\{\frac{1}{2}+\frac{19}{256}\right\} .
$$

Now choose $u_{2} \in P_{T}\left(x_{2}\right)=\left\{\frac{1}{2}+\frac{19}{256}\right\}$, that is, $u_{2}=\frac{1}{2}+\frac{19}{256}$. Then

$$
\begin{aligned}
& z_{2}=(1-\gamma) x_{2}+\gamma u_{2}=\frac{1}{2}\left(\frac{1}{2}+\frac{19}{128}\right)+\frac{1}{2}\left(\frac{1}{2}+\frac{19}{256}\right)=\frac{1}{2}+\frac{57}{512}, \\
& P_{T}\left(z_{2}\right)=\left\{\frac{2 z_{2}+1}{4}\right\}=\left\{\frac{2\left(\frac{1}{2}+\frac{57}{512}\right)+1}{4}\right\}=\left\{\frac{1}{2}+\frac{57}{1024}\right\} .
\end{aligned}
$$

Choose $w_{2} \in P_{T}\left(z_{2}\right)=\left\{\frac{1}{2}+\frac{57}{1024}\right\}$, that is, $w_{2}=\frac{1}{2}+\frac{57}{1024}$. Then

$$
\begin{aligned}
& y_{2}=(1-\beta) u_{2}+\beta w_{2} \\
& =\frac{1}{2}\left(\frac{1}{2}+\frac{19}{256}\right)+\frac{1}{2}\left(\frac{1}{2}+\frac{57}{1024}\right)=\frac{1}{2}+\frac{133}{2048} \\
& P_{T}\left(y_{2}\right)=\left\{\frac{2 y_{2}+1}{4}\right\}=\left\{\frac{2\left(\frac{1}{2}+\frac{133}{2048}\right)+1}{4}\right\}=\left\{\frac{1}{2}+\frac{133}{4096}\right\} .
\end{aligned}
$$

Choose $v_{2} \in P_{T}\left(y_{2}\right)=\left\{\frac{1}{2}+\frac{133}{4096}\right\}, v_{2}=\frac{1}{2}+\frac{133}{4096}$. Then

$$
\begin{aligned}
x_{3} & =(1-\alpha) v_{2}+\alpha w_{2} \\
& =\frac{1}{2}\left(\frac{1}{2}+\frac{133}{4096}\right)+\frac{1}{2}\left(\frac{1}{2}+\frac{57}{1024}\right)=\frac{1}{2}+\frac{361}{8192}<\frac{1}{2}+\frac{1}{6} .
\end{aligned}
$$

In a similar way, $x_{4}<\frac{1}{2}+\frac{1}{8}, x_{5}<\frac{1}{2}+\frac{1}{10}, \ldots, x_{n}<\frac{1}{2}+\frac{1}{n}$. This shows that $\left\{x_{n}\right\}$ converges strongly to a point of $F_{T}=\left[0, \frac{1}{2}\right]$.

We now prove our strong convergence theorem using the following Condition (I) originally due to Senter and Dotson [11].

A multivalued nonexpansive mapping $T: K \rightarrow \mathrm{CB}(K)$ is said to satisfy Condition (I) if there exists a continuous nondecreasing function $f:[0, \infty[\rightarrow[0, \infty[$ with $f(0)=0, f(r)>0$ for all $r \in(0, \infty)$ such that $d(x, T x) \geq f(d(x, F(T))$ for all $x \in K$.

Theorem 2.4 Let $E$ be a real Banach space, $K$ a nonempty closed and convex subset of $E$, $T: K \rightarrow \mathcal{P}(K)$ a multivalued mapping satisfying Condition (I) such that $F(T) \neq \emptyset$ and $P_{T}$ be a quasi-nonexpansive mapping. Then the sequence $\left\{x_{n}\right\}$ as defined in (1.4) converges strongly to a fixed point $p$ of $T$.

Proof From Lemma 2.1, $\lim _{n \rightarrow \infty}\left\|x_{n}-p\right\|$ exists for all $p \in F(T)=F\left(P_{T}\right)$. If $\lim _{n \rightarrow \infty}\left\|x_{n}-p\right\|$ $=0$, there is nothing to prove. Thus we assume $\lim _{n \rightarrow \infty}\left\|x_{n}-p\right\|=c>0$. From the same lemma, we know $\left\|x_{n+1}-p\right\| \leq\left\|x_{n}-p\right\|$, so that

$$
d\left(x_{n+1}, F(T)\right) \leq d\left(x_{n}, F(T)\right) .
$$

Hence, $\lim _{n \rightarrow \infty} d\left(x_{n+1}, F(T)\right)$ exists. We now prove that $\lim _{n \rightarrow \infty} d\left(x_{n+1}, F(T)\right)=0$. Suppose on contrary that $\lim _{n \rightarrow \infty} d\left(x_{n+1}, F(T)\right)=b>0$.

For all $n \in \mathbb{N}$, take

$$
a_{n}=\frac{u_{n}-p}{\left\|x_{n}-p\right\|}, \quad b_{n}=\frac{x_{n}-p}{\left\|x_{n}-p\right\|} .
$$

Then $\left\|b_{n}\right\|=1$ and $\left\|a_{n}\right\| \leq 1$ because $\left\|u_{n}-p\right\| \leq H\left(P_{T}\left(x_{n}\right), P_{T}(p)\right) \leq\left\|x_{n}-p\right\|$. 
Now,

$$
\begin{aligned}
\left\|b_{n}-a_{n}\right\| & =\left\|\frac{x_{n}-p}{\left\|x_{n}-p\right\|}-\frac{u_{n}-p}{\left\|x_{n}-p\right\|}\right\| \\
& =\frac{\left\|x_{n}-u_{n}\right\|}{\left\|x_{n}-p\right\|} \\
& \geq \frac{d\left(x_{n}, T x_{n}\right)}{\left\|x_{n}-p\right\|} \\
& \geq \frac{f\left(d\left(x_{n}, F(T)\right)\right)}{\left\|x_{n}-p\right\|}
\end{aligned}
$$

by Condition (I). Since $f$ is continuous,

$$
\liminf \left\|b_{n}-a_{n}\right\| \geq \frac{f(b)}{c}>0 \quad \text { for all } n \in \mathbb{N} .
$$

We have already established $\lim _{n \rightarrow \infty}\left\|x_{n}-p\right\|=c$ and $\lim _{n \rightarrow \infty}\left\|z_{n}-p\right\|=c$ in Lemma 2.1. Using these two, we have

$$
\begin{aligned}
\lim _{n \rightarrow \infty}\left\|(1-\gamma) b_{n}+\gamma a_{n}\right\| & =\lim _{n \rightarrow \infty}\left\|(1-\gamma) \frac{x_{n}-p}{\left\|x_{n}-p\right\|}+\gamma \frac{u_{n}-p}{\left\|x_{n}-p\right\|}\right\| \\
& =\lim _{n \rightarrow \infty}\left\|\frac{(1-\gamma) x_{n}+\gamma u_{n}-p}{\left\|x_{n}-p\right\|}\right\|=\frac{\lim _{n \rightarrow \infty}\left\|z_{n}-p\right\|}{\lim _{n \rightarrow \infty}\left\|x_{n}-p\right\|}=\frac{c}{c}=1
\end{aligned}
$$

That is,

$$
\lim _{n \rightarrow \infty}\left\|(1-\gamma) b_{n}+\gamma a_{n}\right\|=1 .
$$

Now Lemma 1.3 implies that $\lim _{n \rightarrow \infty}\left\|b_{n}-a_{n}\right\|=0$, a contradiction to $\liminf _{n}\left\|b_{n}-a_{n}\right\|>0$. Thus we have $\lim _{n \rightarrow \infty} d\left(x_{n+1}, F(T)\right)=0$, and so

$$
\lim _{n \rightarrow \infty}\left\|x_{n}-p\right\|=0
$$

Hence, the sequence $\left\{x_{n}\right\}$ converges strongly to a fixed point $p$ of $T$.

To testify our above theorem, we give the following example.

Example 2.5 Consider the Banach space $(\mathbb{R},\|\cdot\|)$ and $K=[1, \infty)$. Obviously, $K$ is a nonempty closed and convex subset of $\mathbb{R}$. Define $T: K \rightarrow \mathcal{P}(K)$ as

$$
T x=\left[1,1+\frac{x}{2}\right] \text {. }
$$

Then $F_{T}=[1,2]$. Let $\alpha=\beta=\gamma=\frac{1}{2}$. Define a continuous and nondecreasing function $f:[0, \infty) \rightarrow[0, \infty)$ by $f(r)=\frac{r}{4}$. First, we show that $d(x, T x) \geq f\left(d\left(x, F_{T}\right)\right)$ for all $x \in K$.

Indeed, when $x \in F_{T}=[1,2], d(x, T x)=0=f\left(d\left(x, F_{T}\right)\right)$.

When $x \in(2, \infty)$,

$$
d(x, T x)=d\left(x,\left[1,1+\frac{x}{2}\right]\right)=\left|x-\left(1+\frac{x}{2}\right)\right|=\frac{x-2}{2},
$$

and

$$
f(d(x, F(T)))=f(d(x,[1,2]))=f(|x-2|)=\frac{x-2}{4} .
$$

Hence, $d(x, T x) \geq f\left(d\left(x, F_{T}\right)\right)$ for all $x \in K$. 
Note that $P_{T}(x)=\{x\}$ when $x \in[1,2]$. If $x \in(2, \infty)$, then

$$
\begin{aligned}
P_{T}(x) & =\left\{y \in T x:|y-x|=d\left(x,\left[1,1+\frac{x}{2}\right]\right)\right\} \\
& =\left\{y \in T x:|y-x|=\left|x-\left(1+\frac{x}{2}\right)\right|=\left|\frac{x}{2}-1\right|\right\} \\
& =\left\{y \in T x:|y-x|=\frac{x}{2}-1\right\} \\
& =\left\{y=1+\frac{x}{2}\right\} .
\end{aligned}
$$

Next, $P_{T}$ is quasi-nonexpansive for all $x \in K$. The case of $[0,2]$ is trivial. Thus we take $x>2$.

$$
H\left(P_{T}(x), P_{T}(p)\right)=H\left(\left\{1+\frac{x}{2}\right\},\{p\}\right)=\left|1+\frac{x}{2}-p\right| \leq|x-p| .
$$

Finally, we generate a sequence $\left\{x_{n}\right\}$ as defined in (1.4) and show that it converges strongly to a fixed point of $T$.

Choose $x_{1}=3 \in K=[1, \infty), P_{T}\left(x_{1}\right)=1+\frac{3}{2}=\left\{\frac{5}{2}\right\}$ and $u_{1} \in P_{T}\left(x_{1}\right)=\left\{\frac{5}{2}\right\}$. That is, $u_{1}=\frac{5}{2}$. Then

$$
z_{1}=(1-\gamma) x_{1}+\gamma u_{1}=\frac{1}{2}(3)+\frac{1}{2}\left(\frac{5}{2}\right)=\frac{11}{4}
$$

and

$$
P_{T}\left(z_{1}\right)=\left\{1+\frac{z_{1}}{2}\right\}=\left\{1+\frac{\frac{11}{4}}{2}\right\}=\left\{\frac{19}{8}\right\} .
$$

Choose $w_{1} \in P_{T}\left(z_{1}\right)=\left\{\frac{19}{8}\right\}$. That is, $w_{1}=\frac{19}{8}$. Then

$$
y_{1}=(1-\beta) u_{1}+\beta w_{1}=\frac{1}{2}\left(\frac{5}{2}\right)+\frac{1}{2}\left(\frac{19}{8}\right)=\frac{39}{16},
$$

and $P_{T}\left(y_{1}\right)=\left\{1+\frac{y_{1}}{2}\right\}=\left\{1+\frac{\frac{39}{16}}{2}\right\}=\left\{\frac{71}{32}\right\}$.

Choosing $v_{1} \in P_{T}\left(y_{1}\right)=\left\{\frac{71}{32}\right\}$, we get $x_{2}=\frac{1}{2}\left(\frac{71}{32}\right)+\frac{1}{2}\left(\frac{19}{8}\right)=\frac{147}{64}=2+\frac{19}{64}<2+\frac{1}{2}$ and $P_{T}\left(x_{2}\right)=\left\{1+\frac{x_{2}}{2}\right\}=\left\{1+\frac{\frac{147}{64}}{2}\right\}=\left\{\frac{275}{128}\right\}$.

Continuing in this way, we get $x_{n}<2+\frac{1}{n}$. This shows that $\left\{x_{n}\right\}$ converges strongly to a point of $F_{T}=[1,2]$.

Now we approximate fixed points of the mapping $T$ through weak convergence of the sequence $\left\{x_{n}\right\}$ defined in (1.4).

Theorem 2.6 Let $E$ be a uniformly convex Banach space satisfying Opial's condition and $K$ be a nonempty closed convex subset of $E$. Let $T: K \rightarrow \mathcal{P}(K)$ be a multivalued mapping such that $F(T) \neq \emptyset$ and $P_{T}$ be a quasi-nonexpansive mapping. Let $\left\{x_{n}\right\}$ be the sequence as defined in (1.4). Let $I-P_{T}$ be demiclosed with respect to zero. Then $\left\{x_{n}\right\}$ converges weakly to a fixed point of $T$.

Proof Let $p \in F(T)=F\left(P_{T}\right)$. From the proof of Lemma 2.1, $\lim _{n \rightarrow \infty}\left\|x_{n}-p\right\|$ exists for all $p$. Now we prove that $\left\{x_{n}\right\}$ has a unique weak subsequential limit in $F(T)$. To prove this, let $z_{1}$ and $z_{2}$ be weak limits of the subsequences $\left\{x_{n_{i}}\right\}$ and $\left\{x_{n_{j}}\right\}$ of $\left\{x_{n}\right\}$, respectively. By (2.13), there exists $u_{n} \in T x_{n}$ such that $\lim _{n \rightarrow \infty}\left\|x_{n}-u_{n}\right\|=0$. Since $I-P_{T}$ is demiclosed with respect to zero, we obtain $z_{1} \in F\left(P_{T}\right)=F(T)$. In the same way, we can prove that $z_{2} \in F(T)$. 
Next, we prove the uniqueness. For this, suppose that $z_{1} \neq z_{2}$. Then by Opial's condition, we have

$$
\begin{aligned}
\lim _{n \rightarrow \infty}\left\|x_{n}-z_{1}\right\| & =\lim _{n_{i} \rightarrow \infty}\left\|x_{n_{i}}-z_{1}\right\| \\
& <\lim _{n_{i} \rightarrow \infty}\left\|x_{n_{i}}-z_{2}\right\| \\
& =\lim _{n \rightarrow \infty}\left\|x_{n}-z_{2}\right\| \\
& =\lim _{n_{j} \rightarrow \infty}\left\|x_{n_{j}}-z_{2}\right\| \\
& <\lim _{n_{j} \rightarrow \infty}\left\|x_{n_{j}}-z_{1}\right\| \\
& =\lim _{n \rightarrow \infty}\left\|x_{n}-z_{1}\right\|,
\end{aligned}
$$

which is a contradiction. Hence, $\left\{x_{n}\right\}$ converges weakly to a point in $F(T)$.

\section{References}

[1] Abbas, M., Nazir, T.: A new faster iteration process applied to constrained minimization and feasibility problems. Mathematicki Vesnik, 106, 1-12 (2013)

[2] Gorniewicz, L.: Topological Fixed Point Theory of Multivalued Mappings, Kluwer Academic Pub., Dordrecht, Netherlands, 1999

[3] Jung, J. S.: Strong convergence theorems for multivalued nonexpansive nonself mappings in Banach spaces. Nonlinear Anal., 66, 2345-2354 (2007)

[4] Khan, S. H., Yildirim, I.: Fixed points of multivalued nonexpansive mappings in Banach spaces. Fixed Point Theory Appl., 2012, 73, 9pp. (2012)

[5] Markin, J. T.: Continuous dependence of fixed point sets. Proc. Amer. Math. Soc., 38, 545-547 (1973)

[6] Nadler, S. B., Jr.: Multivalued contraction mappings. Pacific J. Math., 30, 475-488 (1969)

[7] Opial, Z.: Weak convergence of the sequence of successive approximations for nonexpansive mappings. Bull. Amer. Math. Soc., 73, 591-597 (1967)

[8] Panyanak, B.: Mann and Ishikawa iterative processes for multivalued mappings in Banach spaces. Comp. Math. Appl., 54, 872-877 (2007)

[9] Sastry, K. P. R., Babu, G. V. R.: Convergence of Ishikawa iterates for a multivalued mapping with a fixed point. Czechoslovak Math. J., 55, 817-826 (2005)

[10] Schu, J.: Weak and strong convergence to fixed points of asymptotically nonexpansive mappings. Bull. Austral. Math. Soc., 43, 153-159 (1991)

[11] Senter, H. F., Dotson, W. G.: Approximatig fixed points of nonexpansive mappings. Proc. Amer. Math. Soc., 44(2), 375-380 (1974)

[12] Shahzad, N., Zegeye, H.: On Mann and Ishikawa iteration schemes for multi-valued maps in Banach spaces. Nonlinear Anal., 71(3-4), 838-844 (2009)

[13] Song, Y., Cho, Y. J.: Some notes on Ishikawa iteration for multivalued mappings. Bull. Korean. Math. Soc., 48(3), 575-584 (2011)

[14] Song, Y., Wang, H.: Erratum to "Mann and Ishikawa iterative processes for multivalued mappings in Banach spaces" [Comp. Math. Appl., 54, 872-877 (2007)]. Comp. Math. Appl., 55, 2999-3002 (2008) 